\title{
Improvement in vanadium-containing titanomagnetite processing technology
}

\author{
A V Kushnarev', K V Mironov ${ }^{1}$, S A Zagainov ${ }^{2,3}$ and A A Forshev ${ }^{1}$ \\ ${ }^{1}$ EVRAZ NTMK, ul. Metallurgov, 1, Nizhnij Tagil, Sverdlovskaya oblast, 622025, \\ Russia \\ ${ }^{2}$ Ural Federal University named after the First President of Russia B N Yeltsin, 19, \\ Mira str., Yekaterinburg, 620000, Russia \\ E-mail: ${ }^{3}$ s.a.zagaynov@urfu.ru
}

\begin{abstract}
The article describes the modern technology of iron smelting from vanadiumcontaining titanomagnetite. The complex of research presented by the NTMK team and the leading research teams of the Ural Institute of metals, the metallurgical Institute of the Ural branch of the Russian Academy of Sciences, and the Ural Federal University is the basis for achieving high productivity of the blast furnaces EVRAZ NTMK. The presented research and development works are the basis for the technology of metallurgical processing of vanadiumcontaining titanomagnetite. The developed technology makes it possible to achieve high rates of melting intensity and total consumption of carbon contained in the fuel. Such indicators are achieved by reconstruction, namely by changing the line of the working space of the blast furnace. Modern loading devices were used, energy-efficient technology of coal-dust fuel intake was introduced, and the oxygen content in the air was increased. Considerable attention is paid to the analysis of the domain process and problems of domain melting of titanomagnetite. Particular attention is paid to the implementation of measures to reduce the content of titanium in cast iron.
\end{abstract}

\section{Introduction}

A package of research and development works performed by the NTMK team and by leading research teams of OJSC 'Ural Institute of Metals', Metallurgical Institute of Ural Branch of the Russian Academy of Sciences, and Ural Federal University is the basis for achieving high performance of blast furnaces at JSC EVRAZ NTMK. The development work was devoted to the metallurgical processing of vanadium-containing titanomagnetite $[1,2,4]$. Significant attention is devoted to the analysis of the blast-furnace process and problems of blast-furnace smelting of titanomagnetite [3,6]. Materials provided by different information sources concerning the subject $[16,17]$ were reviewed in the study.

Special attention was given to the implementation of measures to reduce the occurrence of titanium in cast iron $[5,7,11]$. Specialists focus on the impact of base-to-acid ratio on crystallization properties of titanium-containing blast furnace slag [14-16].

\section{Material and Research Methods}

Thermodynamic analysis [5-7] showed that the main reaction of titanium oxide during reduction and transformation into cast iron is the reaction: $\mathrm{TiO}+\mathrm{C}=\mathrm{TiC}+\mathrm{CO}$. The reaction occurs with an increase in the volume of gas. Therefore, increasing pressure prevents the formation of titanium carbide. The equilibrium concentration of $\mathrm{TiC}$ in cast iron at a pressure of $0.40-0.45$ is $0.7-0.5 \%$. The 
actual concentration of titanium in cast iron is $0.20 \%$. This is relevant in connection with the protection of furnaces from exposure to materials containing titanium [28].

In the course of the study, the melt movement conditions were analyzed during the melting of titanomagnetite [8-10] and recommendations were developed for stabilizing the profile of melting products during the melting of vanadium cast iron [12]. For blast furnaces, a specific capacity of more than $3.0 \mathrm{t} / \mathrm{m}^{3}$ was achieved, which is the best result in the Russian Federation.

\section{Results and Discussion}

The raw material base of the complex is the Kachkanarskoye field. The specificity of vanadium smelting is related to the presence of titanium in the charge, which is partially dissolved in cast iron. This leads to the formation of refractory compounds. These compounds (nitrides and carbonitrides) under normal conditions lead to an increase in vanadium losses and the production of metal with slag, furnace failures, and complications when pouring melting products.

The equation for calculating the content of titanium in cast iron $\Delta$ [Ti] relative to the base value [Ti] is obtained from the analysis of physical and chemical processes that determine the extraction of titanium [7-15], taking into account the parameters that determine the change in the content of titanium in cast iron.

$$
\frac{\Delta[\mathrm{TiO}]}{[\mathrm{TiO}]}=\frac{\Delta \mathrm{TiO}_{2}^{\text {mix }}}{\mathrm{TiO}_{2}^{\text {mix }}}+\frac{\Delta K_{r}}{K_{r}}-\frac{\Delta P}{P}-k_{1} \frac{\Delta(\mathrm{MnO})}{(\mathrm{MnO})}-k_{2} \frac{\Delta P_{d a y}}{P_{d a y}}-k_{3} \frac{\Delta C S R}{C S R}-k_{4} \frac{\Delta \eta}{\eta}
$$

Where $\mathrm{TiO}_{2}^{m i x}$ - content of $\mathrm{TiO}_{2}$ in batch mixture, $\% ; K_{r}$ - reaction equilibrium constant of titanium carbide formation, which is calculated with the use of mid-range temperature of melted slag in the lower section of a furnace; $P$ - blast pressure, $\mathrm{kPa}$; $(\mathrm{MnO})$ - content of $\mathrm{MnO}$ in slag, \%; CSR coke hot strength indicator, $\% ; \eta$ - slag viscosity, Pa-s; $k_{1}-k_{4}-$ factors, which were found with the use of mathematical model approach. A comparison of titanium content in cast iron calculated with the use of equation (1) with actual content is given in Figure 1.

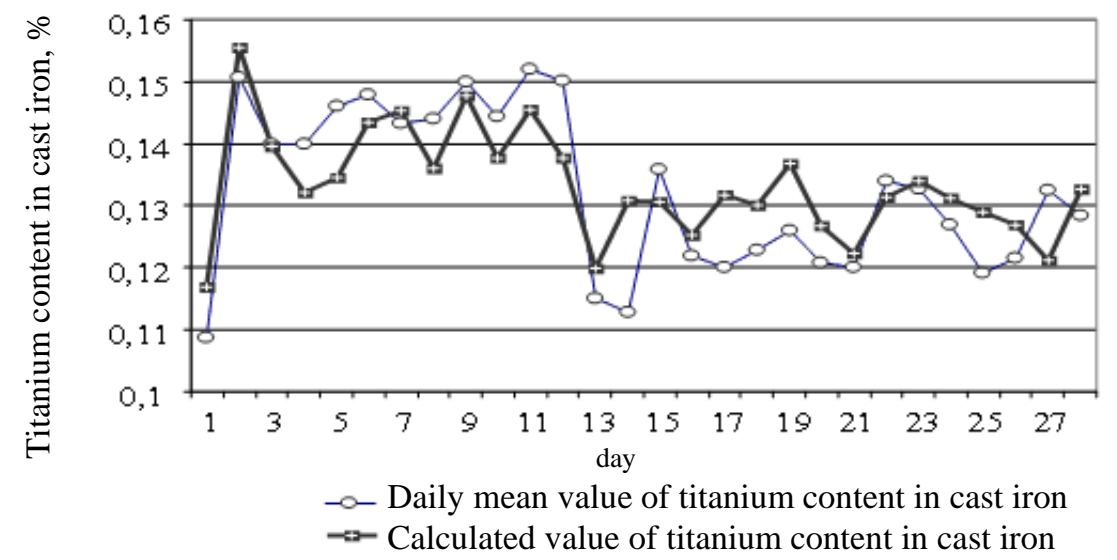

Figure 1. A comparison of titanium content in cast iron calculated with the use of equation (2) with actual content.

One of the major activities ensuring favorable conditions for the production of cast iron with low titanium content is high smelting rate. Analysis of the blast furnace work has shown that increasing of the furnace production rate is accompanied by an increase in the ratio of $\left(\mathrm{TiO}_{2}\right)$ in slag to titanium content in cast iron [Ti] (Figure 2). 


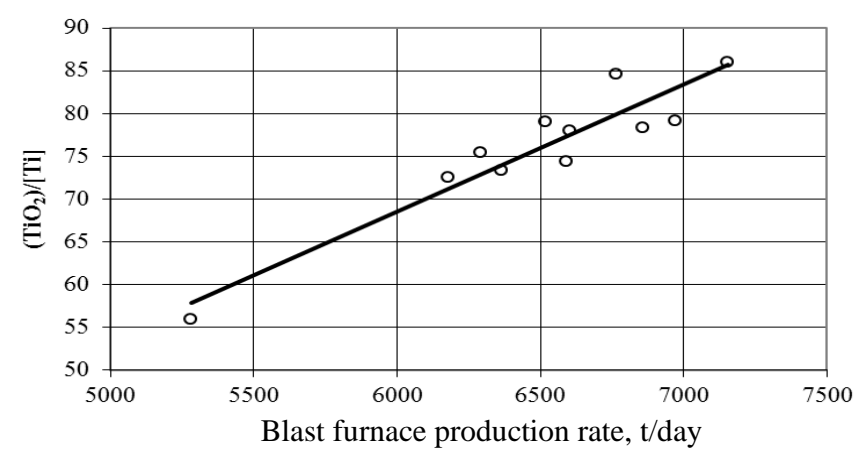

Figure 2. Influence of blast furnace production rate on titanium recovery when silicon content in cast iron is less than $0.09 \%$.

Work of blast furnace with high pressure under the blast-furnace top is provided by the use of bellless top charger. Effectiveness of blast-furnace work with increased pressure under the blast-furnace top is given in Figure 3.

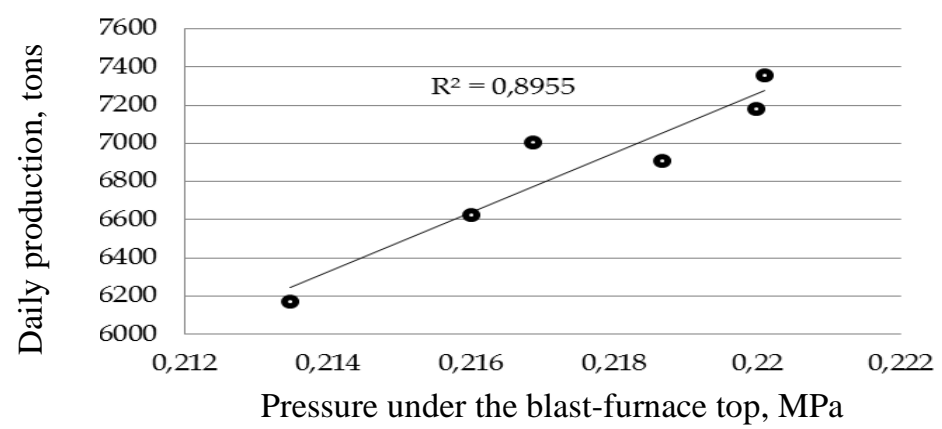

Figure 3. Daily production as a function of pressure under the blast-furnace top.

The increase of solubility of titanium in cast iron impedes the process of titanium carbides formation. The increase of solubility is achieved by the reduction of silicon content in cast iron. Manganese oxides also contribute to the destruction of titanium carbides. Currently, blast furnaces produce cast iron with silicon content ranging between $0.05-0.07 \%$ and with the maximum allowable (according to requirements for ferrovanadium production) content of manganese in cast iron.

An opportunity to improve blast furnace production rate arose after the furnace line had been changed. On the basis of an analysis of data on the work of blast furnaces of an older design, it was believed that the increase of oxygen content in the air blast should not be accompanied by the increase of tuyere gas temperature [16].

Differential equation describing batch mixture temperature variation $\left(t_{\text {mix }}\right)$ depending on the height of the furnace is as follows:

$$
\frac{d t}{d h}=\frac{\alpha}{w_{\text {mix }} c_{\text {app }}}\left(t_{g}-t_{\text {mix }}\right),
$$

Where $\alpha$ - heat transfer factor, $\mathrm{W} / \mathrm{m}^{3} \mathrm{~K} ; w_{\text {mix }}$ - speed of batch mixture movement, $\mathrm{m} / \mathrm{s} ; c_{a p p}-$ apparent heat capacity of a batch mixture, $\mathrm{J} / \mathrm{m}^{3} \mathrm{~K} ; t_{g}$ - temperature of gas entering the bed.

Conditions, under which the theoretical flame temperature increases while the batch mixture temperature upon exiting the bed is maintained, are provided by the constancy of (2). Apparent heat capacity of a batch mixture depends on the amount of recovery additives, a specific yield of slag, and specific coke consumption. Calculations have shown that the dominant factors in heat transfer analysis are speed of batch mixture movement and theoretical tuyere gas temperature. In this case, the maintenance of (2) at the same level is achieved if the following conditions apply: 


$$
\frac{\Delta t_{g}}{t_{g}-t_{m i x}}=\frac{\Delta w_{m i x}}{w_{m i x}}
$$

As can be seen, the ratio (3) is equal to blast furnace production rate variation. Calculations have shown that for every 1 percent of the increase in the production rate the acceptable increase of theoretical tuyere gas temperature is $6.0-7.5^{\circ} \mathrm{C}$.

Taking account of the fact that an increase of oxygen content in the air blast of $1 \%$ results in increase of production rate of 3.5-4.0\% it has been calculated that for each percent of the increase of oxygen content in the air blast the increase of theoretical flame temperature for $15-20{ }^{\circ} \mathrm{C}$ is acceptable.

During the analysis of the effectiveness of blast furnace work with the use of oxygen, the working period of the blast furnace no. 5 was divided on 3 periods (table 1). Annual averages were used. During the first period, the furnace had been working with the oxygen content of less than $26 \%$ (the years 2006-2008). The second period is characterized by an increase of oxygen content in the air blast with a simultaneous increase in the natural gas consumption and with almost constant theoretical temperature. The second period is characterized by the implementation of blast-furnace smelting technology with the use of pulverized coal fuel.

Blast furnace work indicators with varying degrees of oxygen content in the air blast.

The analysis results have shown that it is possible, useful and effective to have an increased oxygen content in the air blast when smelting cast iron out of vanadium-containing titanomagnetite.

Forced work of blast furnaces is ensured by the range of measures aimed at increasing the hot strength of coke. The task has been solved through the choice of a batch mixture for carbonization and through the use of a petroleum additive.

Implementation of cast-iron smelting technology with the use of pulverized coal fuel was a significant factor ensuring the reduction of specific coke consumption [24, 25].

Injection of pulverized coal fuel into the blast furnace leads to changes in the work of the furnace and creates certain problems and hazards during smelting.

Theoretical analysis of hazards has shown that the main factor determining the effectiveness of blast-furnace work with the use of pulverized coal fuel is variations in gas tightness of a bed in the area of the viscoplastic state. Taking into account that pulverized coal fuel is a hydrocarbon additive its impact on specific consumption of coke and pressure differential in the lower part of the bin has been analyzed. In addition, it was assumed that $0.40-0.45 \mathrm{~m}^{3}$ of oxygen per kilo of pulverized coal fuel, and $3.75 \mathrm{~m}^{3}$ of natural gas per kilo of carbon were injected into the furnace.

The calculations have shown that there are two working modes for the blast-furnace with the use of pulverized coal fuel. In the first mode can be achieved increased performance of the furnace, and in the second mode, an increase of pulverized coal fuel consumption is achieved through the maximum possible reduction of specific consumption of coke while reducing smelting intensity.

Daily production as a function pulverized coal fuel consumption is given in Figure 4.

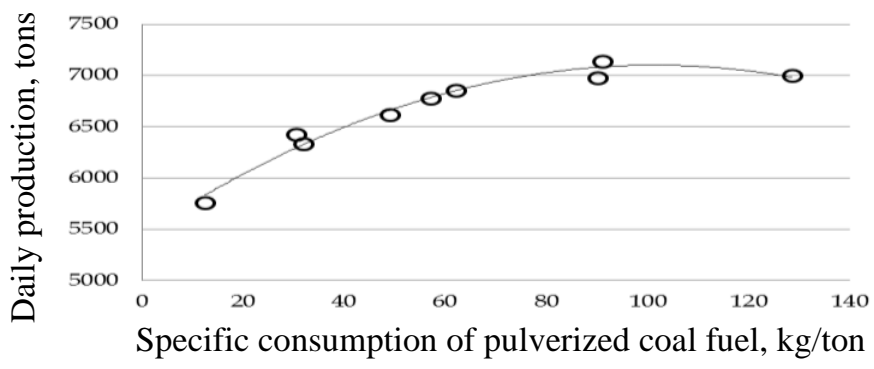

Figure 4. Daily production as a function of pulverized coal fuel consumption. 
Obtained functions have shown that when using pulverized coal fuel, it is possible to choose such pulverized coal fuel and natural gas consumption rates at which either minimum coke consumption or maximum performance of the furnace can be achieved.

Nowadays the blast furnaces work in high-performance mode with optimum relationship between main fuel types (see Table 2).

Table 1. Main indicators of the blast furnaces work.

\begin{tabular}{lcc}
\hline Indicator & BF no. 5 & BF no. 7 \\
\hline Specific production rate, $\mathrm{t} / \mathrm{m}^{3}$ day & 3.11 & 3.27 \\
Specific natural gas consumption rate, $\mathrm{M}^{3} /$ ton of cast iron & 115.1 & 114.0 \\
Specific pulverized coal fuel consumption rate $\mathrm{kg} / \mathrm{ton}$ of & & \\
cast iron & 46.8 & 66.3 \\
Specific coke consumption rate $\mathrm{kg} / \mathrm{ton}$ of cast iron & 367.7 & 338.2 \\
\hline
\end{tabular}

It should be noted that titanium containment in cast iron did not increase with the use of pulverized coal fuel (Figure 5).

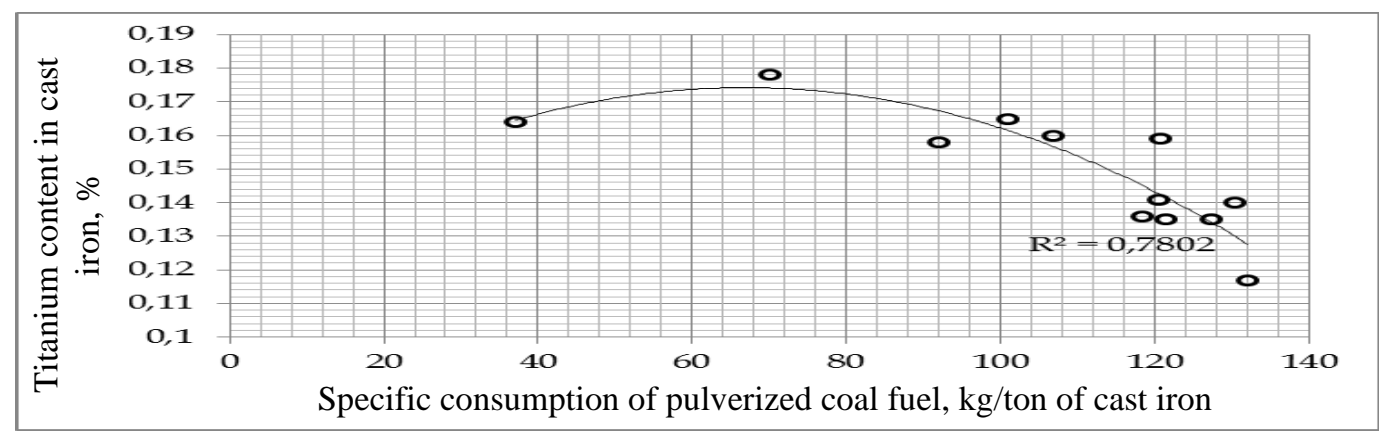

Figure 5. The titanium content in cast iron as a function of pulverized coal fuel consumption.

\section{Conclusions}

Modern technology of cast iron smelting out of vanadium-containing titanomagnetite has been implemented at JSC EVRAZ NTMK. The technology has made it possible to achieve one of the best indicators of smelting intensity and total fuel carbon consumption rate in the Russian Federation.

Such indicators were achieved through renovation - the line of blast furnace working space had been changed, modern charging devices have been used, energy-efficient technology of pulverized coal fuel injection has been implemented, and oxygen content in the air has been increased.

\section{References}

[1] Smirnov L A, Deryabin Yu A and Shavrin S V 1990 Metallurgical Processing of Vanadiumcontaining Titanomagnetite (Chelyabinsk: Metallurgy) p 256

[2] Volkov V V, Filippov V V and Gavrilyuk G G 2000 Experience of Titanomagnetite Processing in Blast Furnaces Steel no 11 pp 24-8

[3] Zakharov A I, Rudin V S, Filippov V V and Shavrin S V 2004 Analysis of the Blast-furnace Process in Conditions of Smelting of Low-siliceous Vanadium Cast Iron Steel no 4 pp 14-6

[4] Nosov S K, Filippov V V and Shavrin S V 2003 Problems of Blast-furnace Smelting of Titanomagnetite and Ways of Addressing the Problems Steel no 6 p 6-9

[5] Kushnarev A V, Shavrin S V, Zagainov S A and Sobianina O N et al 2007 Implementation of Measures to Reduce the Occurrence of Titanium in Cast Iron Collected works of the International conference dedicated to quality improvement of metal used in the transport industry (Nizhny Tagil: Publishing House of JSC NTMK) p 121-23

[6] Zagainov S A, Sobianina O N and Filippov V V et al 2008 Analysis of Blast-furnace Smelting in Production of Vanadium Cast Iron Collected works of the International research-to-practice 
conference 'Improving the Quality of Education and Scientific Research' within the framework of the VII Satbayev Readings (Ekibastuz: Publishing House of Ekibastuz Institution of Engineering and Technology named after Academician K I Satbayev) pp 370-71

[7] Kushnarev AV, Shavrin S V, Zagainov S A and Sobianina O N et al 2008 Collected works of the 3rd International conference 'Transmet-2007' Implementation of Measures to Reduce the Occurrence of Titanium in Cast Iron (Yekaterinburg: Publishing House of USTU) pp 169-71

[8] Sobianina O N, Filatov S V and Zagainov S A 2008 Analysis of Conditions of Melt Movement in the Blast-furnace Well During Smelting of Titanomagnetite News of Higher Educational Institutions. Ferrous Metallurgy no 4 pp 69-70

[9] Sobianina O N, Filatov S V and Zagainov S A 2012 Analysis of Specificities of Titanium Recovery in Blast Furnace Steel no 3 pp 9-11

[10] Sobianina O N and Zagainov S A 2007 Specificities of Melt Movement in the Blast-furnace Well During Smelting of Titanomagnetite Ingoing Materials Collected works of the XIII Reporting Scientific Conference of Young Scientists of USTU (Yekaterinburg: Publishing House of USTU) pp 230-2

[11] Kushnarev A V, Shavrin S V, Zagainov S A and Sobianina O N et al 2007 Implementation of Measures to Reduce the Occurrence of Titanium in Cast Iron Collected works of the International conference dedicated to quality improvement of metal used in the transport industry (Nizhny Tagil: Publishing House of JSC NTMK) pp 121-3

[12] Zagainov S A, Onorin O P and Sobianina O N et al 2008 Development and Issuance of Recommendations on Stabilization of Smelting Products Profile During Vanadium Cast Iron Smelting Bulletin 'Ferrous Metallurgy', JSC Chermetinformatsiya no 7 p 70

[13] Jianlong Wu, Hui Chen, Jian Sun, Zhixing Zhao, Wei Wang and Yan Zhang 2019 Metallurgical properties and furnace protection practice of different titanium-bearing burdens, Ironmaking \& Steelmaking

[14] Zhao W, Chu M and Liu Z et al Aug 2019 High-Temperature Interactions Between VanadiumTitanium Magnetite Carbon Composite Hot Briquettes and Pellets Under Simulated Blast Furnace Conditions Metallurgical and materials transactions b-process metallurgy and materials processing science vol $\mathbf{5 0}$ (Edition 4) pp 1878-95

[15] Zhao W, Chu M and Wang H et al Jan 152019 Reduction behavior of vanadium-titanium magnetite carbon composite hot briquette in blast furnace process Powder technology vol $\mathbf{3 4 2}$ pp 214-23

[16] Hu M, Wei R and Gao L et al Mar 2018 Effect of the Basicity on the Crystallization Behavior of Titanium Bearing Blast Furnace Slag High temperature materials and processes vol 37 (Edition 3) pp 193-200

[17] Li W, Wang N and Fu G et al Feb 152018 Influence of $\mathrm{TiO} 2$ addition on the oxidation induration and reduction behavior of Hongge vanadium titanomagnetite pellets with simulated shaft furnace gases Powder technology vol 326 pp 137-45 